Disponível em:

http://editora.unoesc.edu.br/index.php/race

Race, Joaçaba, v. 14, n. 3, p. 1175-1204, set./dez. 2015

\title{
MUDANÇAS NAS ROTINAS CONTÁBEIS: CONTRADIÇÕES INSTITUCIONAIS E PRÁXIS HUMANAS
}

\section{Changes in accounting routines: institutional contradictions and human praxis}

Franciele Wrubel

E-mail: franciele_wrubel@yahoo.com.br

Mestre em Ciências Contábeis pela Universidade do Vale do Rio dos Sinos; doutoranda em Ciências contábeis e Administração pela Universidade Regional de Blumenau; Professora da Universidade Estadual do Oeste do Paraná.

Leandro Augusto Toigo

E-mail: leandro.toigo@unioeste.br

Mestre em Ciências Contábeis pela Universidade do Vale do Rio dos Sinos; doutorando em Ciências contábeis e Administração pela Universidade Regional de Blumenau; Professor da Universidade Estadual do Oeste do Paraná. Endereço para contato: Rua Universitária, 1619, Universitário, 85819-110, Cascavel, Paraná, Brasil.

\section{Carlos Eduardo Facin Lavarda \\ E-mail:clavarda@furb.br}

Doutor em Contabilidade pela Universidade de Valência; Mestre em Ciências Contábeis pela Universidade do Vale do Rio dos Sinos; Professor do Departamento de Contabilidade da Universidade Regional de Blumenau. Bolsista CNPq. 


\section{Resumo}

Objetivou-se, neste estudo, identificar os fatores que proporcionam contradições, práxis e mudanças institucionais em rotinas contábeis. Foi elaborado e aplicado um questionário estruturado com 56 questões, construído a partir dos modelos de Tolbert e Zucker (1999) e Seo e Creed (2002). Foram obtidos 43 questionários respondidos, os quais, por sua vez, foram tratados por meio da análise fatorial, com o uso do método de análise de componentes principais com rotação Varimax, que permite a redução de variáveis ou a redução de fatores. Os testes de Kaiser-Meyer-Olkin (KMO), de esfericidade de Barlett, Alpha de Cronbach e de significância mostram-se adequados. Os resultados apresentam cinco fatores de mudanças institucionais e oito fatores de contradições institucionais e práxis humanas. Conclui-se que dois fatores representam as mudanças provocadas pelos fatores de mercado e legislação, representando $23,645 \%$ da variância, ou seja, $32,107 \%$ da variância total $(73,643 \%)$. Os demais fatores estão fortemente relacionados a mudanças tecnológicas. Na análise das contradições institucionais e práxis humanas, percebe-se que os três fatores mais representativos estão relacionados com desalinhamento de interesses e incompatibilidade institucional (Fator 1; 18,18\%), práxis humanas (Fator 2; 14,107\%) e ineficiência técnica (Fator 3; 11,663\%), com acumulado de $43,45 \%$. No estudo é descrito sobre um contexto específico das rotinas contábeis para os profissionais que atuam na área, são elencados os fatores com peso mais significativo e representativo diante das diversas mudanças institucionais as quais os profissionais vivenciam. Palavras-chave: Rotinas contábeis. Mudanças institucionais. Contradições institucionais. Práxis humanas. Teoria institucional.

\section{Changes in accounting routines: institutional contradictions and human praxis}

\section{Abstract}

With this study, we aimed to identify the factors that provide contradictions, praxis and institutional changes in accounting routines. A structured questionnaire with 56 questions was developed and implemented, constructed from the models of Tolbert and Zucker (1999) and Seo and Creed (2002). Forty-three responses were obtained, which were treated by factor analysis, using the method of analysis of principal components with Varimax rotation, that allows the reduction of variables or the reduction of factors. The tests of Kaiser-Meyer-Olkin (KMO), of sphericity of Barlett, Cronbach's alpha and of significance prove to be adequate. The results show five institutional changes factors and eight institutional contradictions factors and human praxis. It is concluded that two factors account for the changes caused by market factors and legislation, representing $23.645 \%$ of the variance, i.e. $32.107 \%$ of the total variance $(73.643 \%)$. The other factors are strongly related to technological changes. In the analysis of institutional contradictions and human praxis, one realizes that the three most significant factors are related to misalignment of interests and institutional incompatibility (Factor 1; 18.18\%), human praxis (Factor 2; 14.107\%) and technical efficiency (Factor 3; 11.663\%) with cumulate of $43.45 \%$. The study describes about a specific context of accounting routines for professionals working in the area, and it lists the factors with the most significant and representative weight on the various institutional changes that the professionals experience.

Keywords: Accounting routines. Institutional changes. Institutional contradictions. Human praxis. Institutional theory. 


\section{INTRODUÇÃO}

Estudos sobre as mudanças organizacionais ocorridas na gestão das empresas têm sido objeto de investigações da comunidade acadêmica. Entre aqueles que exploraram esse tema, são importantes os que identificam e analisam os artefatos adotados pelas empresas (SOUTES, 2006; YADOMARI et al., 2008), pois técnicas de gestão e práticas de contabilidade podem ser utilizadas de forma combinada para melhorar o desempenho das organizações, conforme suas estratégicas (CHENHALL; LANGFIELD-SMITH, 1998).

Para Burns e Scapens (2000), a necessidade de mudança ocorre em razão dos avanços da tecnologia da informação, da competitividade dos mercados, das diferentes estruturas organizacionais e das novas práticas de gestão disponíveis às organizações. Para Tolbert e Zucker (1999), durante o processo de mudança existe uma preocupação que reflete dois objetivos principais, que remetem a duas premissas: deve haver uma integração entre os componentes estruturais no sistema para que este possa sobreviver, de modo que os componentes sejam partes inter-relacionadas do todo; e o funcionamento de um sistema social depende da contribuição das estruturas existentes, pelo menos para manter um equilíbrio, pois, de outro modo, o sistema não sobreviveria. Partindo do entendimento de que as empresas realizam mudanças em seus controles gerenciais para se manterem atualizadas e suprirem suas necessidades institucionais, uma das teorias que vem sendo utilizada para entender essas mudanças é a teoria institucional (BURNS; SCAPENS, 2000).

Essa teoria já vem sendo a lente e o objeto de pesquisadores, e é possível mencionar alguns de destaque na área da Contabilidade Gerencial, como SitiNabiha e Scapens (2005), quem buscaram entender como ocorre a estabilidade das mudanças na Contabilidade Gerencial de uma empresa e constataram que a estabilidade e a mudança não, necessariamente, são forças contraditórias ou opostas, mas podem se interligar em um processo de evolução de mudanças. Outro estudo foi de Guerreiro et al. (2005) sobre a implantação de um método de programação de orçamento no SESC de São Paulo, indicando um conjunto de fatores associados ao processo de institucionalização do orçamento; observa-se que os fatores motivadores possuem uma influência relativa, superior aos fatores inibidores. Entre as demais pesquisas estão: Guerreiro, Pereira e Rezende (2006), Oyadomari et al. (2008) e Lavarda, Ripoll Feliu e Barrachina Palanca (2009).

Nota-se que os estudos pautados em entender os processos de mudanças das organizações têm tido diversas abordagens e contribuições à literatura da teoria 
institucional. Além disso, focam em artefatos ou contabilidade gerencial, de forma que este estudo se concentra na análise das mudanças institucionais nas rotinas de prestação de serviços de contabilidade e utiliza-se dos achados de Seo e Creed (2002) quando foca nas contradições institucionais e nas práxis humanas.

Popik (2013), com base nos estudos anteriores, constatou que nem mesmo a velha economia institucional ou a nova sociologia institucional têm conseguido explicar, algumas questões, as quais, assim, têm sido muito criticadas por pesquisadores e pensadores, de forma que, buscando contribuir com a literatura existente, Seo e Creed (2002) observam a mudança organizacional sob um aspecto diferente. Em meio aos pesquisadores que contribuíram com o desenvolvimento da teoria institucional nos últimos anos, eles destacam-se. Seo e Creed (2002) baseiam-se na perspectiva dialética de Benson (1977), que enfatiza as contradições institucionais e as práxis no processo de mudança das organizações. Nesse sentido, diversos estudos foram desenvolvidos pelos autores: Burns e Baldvinsdottir (2005); Abrahamsson e Gerdin (2006); Sharma, Lawrence e Lowe (2010); Conrad e Uslu (2011); Bjerregaard e Lauring (2012); Wanderley (2012) e Popick (2013).

$\mathrm{O}$ tema referente a mudanças em contabilidade foi objeto de pesquisas, sendo os principais assuntos: sistemas contábeis, técnicas de contabilidade, a profissão contábil e o papel do contador. Entretanto, pouco foi estudado sobre o porquê e como a contabilidade evoluiu diante de situações organizacionais específicas (BURNS, 2000). Os mesmos autores exemplificam mencionando que as mudanças contábeis podem acontecer pelas mudanças nas rotinas contábeis. Nesse sentido, buscou-se, com este estudo, avaliar as rotinas contábeis dos departamentos contábeis nas empresas e nos escritórios de contabilidade, que, por sua vez, executam rotinas contábeis.

Diante desse cenário, surge a seguinte questão de pesquisa: quais são os fatores que proporcionam contradições, práxis e mudanças institucionais em rotinas contábeis? Para resolver esse problema de pesquisa, utilizou-se questionário elaborado e validado, o qual foi aplicado aos profissionais contábeis.

Justifica-se este estudo porque as mudanças nas rotinas contábeis podem ou não ser bem-sucedidas. Nesse sentido, Wanderley e Cullen (2012) estudaram o caso da Electra, que implantou o Balanced Scorecard, o qual não foi institucionalizado pelo principal motivo da ausência do acúmulo de contradições institucionais. Baseados em Seo e Creed (2002), Burns e Baldvinsdottir (2005) abordam que as contradições criam condições para que ocorra a mudança institucional, e, ainda, que as práxis humanas são responsáveis por colocar as ideias em prática para que as mudanças 
ocorram, sendo estas as intermediadoras do processo de mudança institucional. Cabe a este estudo analisar e relatar à sociedade as contradições e as práxis humanas que provocam mudanças nas rotinas contábeis dos departamentos contábeis e dos escritórios de contabilidade.

\section{REFERENCIAL TEÓRICO}

Com o intuito de esclarecer sobre a teoria institucional e os serviços contábeis, além de estudos relacionados sobre esses assuntos, construiu-se o referencial teórico, apresentando nos tópicos a seguir argumentos encontrados na literatura que possam servir de base a tais temas.

\subsection{SERVIÇOS CONTÁBEIS}

Os profissionais contábeis têm a capacidade de oferecer vários serviços indispensáveis na administração e controle de qualquer tipo de organização. Os serviços contábeis podem ser prestados por profissionais individuais que atuam em setores especializados dentro das organizações ou por meio de profissionais de escritórios de contabilidade, ou seja, empresas contábeis. Thomé (2001, p. 21) "[...] define os serviços prestados pelas empresas contábeis na seguinte ordem: consultoria, contabilidade, administração de pessoal, escrituração fiscal, expediente (ou serviços comerciais), auditoria, perícia e assessoria."

Nesse sentido, o contador desempenha papel de destaque na gestão e controle dos recursos financeiros da empresa, na medida em que estes influenciam a tomada de decisão, uma vez que o gestor inteligente busca se basear em informações contábeis para tomar suas decisões.

Os escritórios contábeis são sociedades civis, constituídas com o objetivo de prestar serviços contábeis para outras organizações industriais, comerciais e outras prestadoras de serviços. A Resolução CFC n. 1.098/07 discrimina duas modalidades de organizações contábeis: escritório individual, caracterizado quando o contabilista, embora sem personificação jurídica, executa suas atividades independentemente do local e do número de empresas ou serviços sob sua responsabilidade; e organização contábil, que se trata de pessoa jurídica de natureza civil, constituída sob a forma de sociedade, tendo por objetivo a prestação de serviços profissionais de contabilidade. Para funcionarem, tais organizações devem estar registradas no Conselho Regional 
de Contabilidade (CRC) do estado de sua jurisprudência, bem como estar sob a legislação do Conselho Federal de Contabilidade (CFC).

Inseridas na abordagem dos serviços prestados, as organizações contábeis possuem muitas rotinas contábeis para oferecer tais serviços. Thomé (2001) aborda que os serviços prestados são: a escrituração contábil, a conciliação de contas, a elaboração de demonstrações financeiras, as declarações fiscais, a contabilidade gerencial, as obrigações acessórias e eletrônicas, entre outros.

O art. 1.179 do Código Civil de 2002 impõe ao empresário manter a escrituração mercantil e fiscal em ordem (MARTINS-COSTA; BRANCO, 2002). Thomé (2001) relata que o departamento fiscal é considerado um setor de risco dentro das organizações contábeis, em razão das elevadas penalidades impostas pelo Poder Público aos contribuintes que não entregam nos prazos as guias dos seus impostos e obrigações acessórias calculadas pelo escritório contábil. Com base na exemplificação, verifica-se que os escritórios contábeis prestam serviços sob constante pressão e buscam se organizar em rotinas sistemáticas para atender às necessidades dos clientes e às necessidades governamentais.

Burns e Scapens (2000) abordam que as mudanças em contabilidade podem ser entendidas em termos de mudanças em rotinas contábeis, que podem ou não ser incorporados nas suposições e convicções de organizações. Tais suposições e convicções, comuns aos membros da organização, são chamadas de instituições.

Práticas contábeis e rotinas emergentes podem ser ditas institucionalizadas quando são plenamente aceitas pela instituição, de tal forma que se tornam formas inquestionáveis de controle contábil. Nesse sentido, elas são características inerentes ao processo de controle contábil, representam formas esperadas de comportamento e definem as relações entre os vários grupos organizacionais (BURNS; SCAPENS, 2000).

\subsection{TEORIA INSTITUCIONAL}

A teoria institucional é considerada o resultado da consonância de influências de proposições teóricas originadas principalmente da ciência política, da sociologia e da economia, que visam à incorporação de ideias de instituições e padrões de comportamentos, regras, valores e cultura, os quais, geralmente, permanecem ocultos nos indivíduos ou empresas (MACHADO-DA-SILVA; GONÇALVES, 1999). Ainda, compreende um conjunto de constructos teóricos, baseados em três 
correntes, cada qual com enfoque da abordagem institucional: a Nova Economia Institucional (NEI); a Velha Economia Institucional (VEI) e a Nova Sociologia Institucional (NSI) (SCAPENS, 1994; BURNS; SCAPENS, 2000; DILLARD; RIGSBY; GOODMAN, 2004; RIBEIRO; SCAPENS, 2006; FREZATTI et al., 2009; MAJOR; RIBEIRO, 2009).

Cruz, Major e Scapens (2009) mencionam que a percepção crucial da teoria institucional sugere que as regras e rotinas devem ser seguidas pelos atores da organização. Isso implica que as organizações reproduzam as formas institucionais impostas externamente, sem modificá-las. Constata-se que a contextualização dada pela teoria institucional nas organizações, por envolver processos e rotinas, tem muita relação com a contabilidade, os artefatos e as práticas da empresa.

Lopes e Iudícibus (2012) destacam que a teoria institucional observa a contabilidade como uma ferramenta interligada à vida das organizações e ao ambiente em que ela está instituída, no qual busca explicar os fatos contábeis por meio de comportamentos, normas, regras, crenças, cultura e modelos que as organizações utilizam para se manterem no ambiente.

O processo de institucionalização apresentado por Burns e Scapens (2000) considera que o campo institucional e o campo das ações modelam e remodelam as instituições, conforme sua influência acumulada ao longo do tempo. Para os autores, existe o campo institucional e o campo da ação; ambos estão em andamento em um processo cumulativo de mudança ao longo do tempo. As regras e rotinas agem ligando esses campos (BURNS; SCAPENS, 2000).

A institucionalização age como um processo profundamente político e reflete diretamente nos interesses dos atores organizacionais que o mobilizam (COVALESKI; DIRSMITH; MICHELMAN, 1993). Os elementos da institucionalização são o indivíduo, a organização e o ambiente (BOFF; BEUREN; GUERREIRO, 2008); o primeiro é ator social ao formular ações estratégicas com base nos significados atribuídos às regras de funcionamento das organizações. Esse assunto foi pesquisado por Reis (2008), que analisou as relações entre indivíduos no interior das organizações, tendo por objetivo observar os comportamentos que produzem uma nova realidade social, que, após um processo de mudança, possa ser institucionalizada.

Para Boff, Beuren e Guerreiro (2008), a organização é reconhecida como arena social ou componente do sistema de relações de um campo específico, formado por atividades padronizadas e articuladas, que expressam normas e regras sociais. O ambiente, por sua vez, independentemente de sua localização geográfica 
no campo externo, representa o setor social composto por organizações que fabricam e oferecem produtos e serviços similares.

\subsection{MUDANÇAS INSTITUCIONAIS}

\subsubsection{Mudanças Institucionais sob o Enfoque de Tolbert e Zucker}

As mudanças institucionais, com base no modelo desenvolvido por Tolbert e Zucker (1999), acontecem a partir de uma inovação. Esse modelo (TOLBERT; ZUCKER, 1999) é aplicado à contabilidade gerencial e é voltado a todas as organizações, além disso, incorpora elementos do ambiente externo, como mudanças tecnológicas, legislação e forças do mercado como impulsionadores da inovação em ambientes de mudança. Nesse modelo, os autores destacam que os processos para a institucionalização são compostos por: habitualização, objetificação e sedimentação.

No processo inerente à institucionalização, é na habitualização, conforme os autores, que ocorre a geração de novos arranjos estruturais em resposta a problemas ou conjuntos de problemas organizacionais específicos e a normalização de tais arranjos em políticas e procedimentos de determinada organização. Já a objetificação está atrelada ao desenvolvimento de certo grau de consenso social entre os entes envolvidos a respeito do valor da estrutura. Estruturas que se objetificaram e foram amplamente disseminadas podem ser descritas como estando no estágio de semiinstitucionalização.

Conforme os autores, na última etapa está a sedimentação, um processo que fundamentalmente se apoia na continuidade histórica da estrutura e, especialmente, em sua sobrevivência pelas várias gerações da organização; a identificação dos fatores que afetam a abrangência do processo de difusão, como, também, a conservação, em longo prazo, de uma estrutura é, assim, a chave para a compreensão desse processo de sedimentação.

\subsubsection{Mudanças institucionais sob o enfoque de Seo e Creed}

A teoria institucional está embasada em entender quanto as mudanças institucionais, são pautadas nos postulados e nas ações dos atores organizacionais advindas tanto interna quanto externamente às instituições (WANDERLEY, 2012). 
Entretanto, de acordo com pesquisadores como Seo e Creed (2002), Burns e Baldvinsdottir (2005) e Wanderley (2012), a teoria institucional não está conseguindo responder a perguntas como: de qual contexto surge a necessidade de mudança? Quando e como os atores organizacionais reconhecem a necessidade de mudança?

Seo e Creed (2002), fundamentados na perspectiva dialética de Benson (1977) apresentaram framework ilustrativo para o entendimento dessa lacuna ao qual a teoria institucional não havia contemplado. Benson (1977) afirma que a visão dialética é comprometida, essencialmente, com o conceito de processo e explica que os processos sociais são ignorados pelas teorias convencionais. Benson (1977) e Seo e Creed (2002) apresentam os quatro princípios básicos: construção social, totalidade, contradições e práxis. A Construção social centra no fato de que relações ordenadas e previsíveis são produzidas e reproduzidas por meio de interações humanas dirigidas por interesses pessoais e de poder, possibilitando que os padrões sociais sejam gradualmente construídos (SEO; CREED, 2002). A totalidade consiste nos fenômenos sociais que devem ser estudados de forma relacionada às suas múltiplas interconexões (BENSON, 1977). Contradição refere-se às diferentes rupturas e inconsistências entre arranjos sociais estabelecidos (SEO; CREED, 2002), e Práxis é como a livre e criativa reconstrução de arranjos sociais, fundamentada nos limites e nas potencialidades atuais das formas sociais, sendo as pessoas possíveis agentes ativos da construção de suas próprias relações sociais (BENSON, 1977).

Para Wanderley et al. (2011), a mudança institucional deve ser entendida como um resultado das interações dinâmicas entre as contradições institucionais e as práxis humanas. Conforme Wanderley (2012), essa mudança que obteve sucesso é motivada pelas fontes de contradições institucionais, que irão acionar e permitir que as práxis humanas introduzam mudanças institucionais promulgadas e reproduzidas ao longo do tempo para se tornarem institucionalizadas. No Quadro 1 são apresentadas as quatro fontes de contradições. 
Quadro 1 - Contradições institucionais

\begin{tabular}{|l|l|}
\hline \multicolumn{2}{|c|}{ CONTRADIÇÕES INSTITUCIONAIS } \\
\hline $\begin{array}{l}\text { Ineficiência } \\
\text { técnica }\end{array}$ & $\begin{array}{l}\text { É a primeira fonte de contradição, provocada quando os arranjos institucionais } \\
\text { entram em conflito com as atividades técnicas e exigências de eficiência da orga- } \\
\text { nização, ou seja, quando os princípios organizacionais e a parte técnica não estão } \\
\text { em conformidade (SEO; CREED, 2002). }\end{array}$ \\
\hline $\begin{array}{l}\text { Não adaptabi } \\
\text { lidade }\end{array}$ & $\begin{array}{l}\text { Em razão da ineficiência técnica, entre outros fatores, as empresas tendem a } \\
\text { mudar ou implementar novos sistemas de controle. Wanderley (2012) aborda que } \\
\text { as contradições podem surgir da não adaptabilidade desses arranjos institucionais } \\
\text { implantados na organização para com o ambiente externo. }\end{array}$ \\
\hline $\begin{array}{l}\text { Incompatibi- } \\
\text { lidade institu- } \\
\text { cional }\end{array}$ & $\begin{array}{l}\text { Também pode surgir de dentro de um ambiente institucional, como, por exemplo, } \\
\text { nas situações de implantação de inovações (CLEMENS; COOK, 1999). As organi- } \\
\text { zaçes estão cada vez mais expostas às contradições institucionais, pois até mesmo } \\
\text { certos sistemas que estão institucionalizados podem vir a ter incompatibilidade com } \\
\text { as expectativas comportamentais decorrentes de arranjos institucionais em diferen- } \\
\text { tes patamares ou setores da organização (SEO; CREED, 2002). }\end{array}$ \\
\hline $\begin{array}{l}\text { Desalinha } \\
\text { mento de } \\
\text { interesses }\end{array}$ & $\begin{array}{l}\text { Os arranjos institucionais são vistos como produtos submetidos a disputas po- } \\
\text { líticas por atores que têm interesses divergentes, assim como poder assimétrico, } \\
\text { desigual (SEO; CREED, 2002). Portanto, os arranjos institucionais acabam re- } \\
\text { fletindo ideias e objetivos dos atores mais poderosos politicamente (BENSON, } \\
\text { 1977). }\end{array}$ \\
\hline
\end{tabular}

Fonte: adaptado de Popik (2013).

Seo e Creed (2002) abordam que as práxis humanas são caracterizadas como principais mediadores entre as contradições e a mudança institucional. Os atores institucionais são os responsáveis para que as mudanças ocorram, assim, as ações motivadoras acontecem por meio de reuniões, treinamentos, cursos e ação coletiva (ABRAHAMSSON; GERDIN, 2006; SHARMA; LAWRENCE; LOWE, 2010; WANDERLEY; CULLEN, 2012).

\subsection{ESTUDOS RELACIONADOS}

Alguns estudos, sob a ótica da teoria institucional, têm sido realizados abrangendo as mudanças na gestão e nos artefatos utilizados. No Quadro 2 seguem alguns exemplos. 
Quadro 2 - Principais estudos relacionados

\begin{tabular}{|c|c|}
\hline $\begin{array}{l}\text { Guerreiro, Pe- } \\
\text { reira e Rezende } \\
(2006)\end{array}$ & $\begin{array}{l}\text { Identificaram aspectos fundamentais de hábitos e rotinas da contabilidade } \\
\text { gerencial. Considerando a necessidade de entendimento da situação da empresa } \\
\text { antes do processo de mudanças, durante o processo e após a implantação, os au- } \\
\text { tores optaram por pesquisa-ação. A busca por respostas foi embasada nas teorias } \\
\text { institucional e da contingência. Dos resultados apontados pelo caso estudado, } \\
\text { destacam-se: a análise dos impactos de contingências ambientais, tornando } \\
\text { ineficazes os hábitos e rotinas de contabilidade gerencial existentes; a dificulda- } \\
\text { de de mudança nos velhos hábitos e rotinas institucionalizados, empregados de } \\
\text { forma inconsciente; e o emprego de diferentes estratégias para a institucionali- } \\
\text { zação dos novos conceitos gerenciais. }\end{array}$ \\
\hline $\begin{array}{l}\text { Oyadomari et al. } \\
(2008)\end{array}$ & $\begin{array}{l}\text { Caráter exploratório. À luz da Teoria Neo institucional visam entender a ado- } \\
\text { ção de artefatos de contabilidade gerencial no ambiente empresarial brasileiro. } \\
\text { A amostra foi não probabilística e abrangeu } 27 \text { empresas de médio e grande } \\
\text { portes. Utilizou-se estatística descritiva para a análise dos questionários. Con- } \\
\text { clui-se que: há uma adoção do tipo cerimonial na implementação dos artefatos; } \\
\text { o mecanismo mimético é o mais importante na adoção desses artefatos; a ob- } \\
\text { tenção do conhecimento sobre novos artefatos ocorre, preponderantemente, } \\
\text { pela forma de socialização do conhecimento; as consultorias têm um papel } \\
\text { importante na adoção dos artefatos; a imposição dos acionistas é pequena, sen- } \\
\text { do, portanto, minimizado o mecanismo coercitivo; e a decisão da escolha dos } \\
\text { artefatos é prerrogativa do corpo diretivo e gerencial da empresa. }\end{array}$ \\
\hline $\begin{array}{l}\text { Lavarda, Ripoll } \\
\text { Feliu e Barra- } \\
\text { china Palanca } \\
(2009)\end{array}$ & $\begin{array}{l}\text { Analisaram o processo interno de mudança de sistemas de contabilidade } \\
\text { gerencial em uma pequena empresa e examinaram como os aspectos desse } \\
\text { processo afetam a institucionalização. Foi utilizada a perspectiva de análise da } \\
\text { velha economia institucional. Estudo de caso. Concluíram que os fatores que } \\
\text { influenciaram positivamente a internalização da institucionalização dos siste- } \\
\text { mas de controle gerencial foram: os conhecimentos e habilidades envolvidos } \\
\text { na mudança; os recursos de informática; a formação do pessoal; a baixa parti- } \\
\text { cipação de peritos externos no sistema de controle gerencial; o incentivo dos } \\
\text { operadores do sistema; as relações de confiança; o processo de planejamento e o } \\
\text { envolvimento do pessoal. }\end{array}$ \\
\hline $\begin{array}{l}\text { Beuren e Ma- } \\
\text { cohon (2011) }\end{array}$ & $\begin{array}{l}\text { Destacam que as pressões institucionais contribuem para as modificações na } \\
\text { contabilidade gerencial. Desse modo, a teoria institucional gera uma perspecti- } \\
\text { va de análise das organizações, que permite verificar seus fenômenos e entender } \\
\text { os diversos aspectos das instituições e seus respectivos processos de institucio- } \\
\text { nalização. }\end{array}$ \\
\hline Popik (2013) & $\begin{array}{l}\text { Identifica como as contradições institucionais e as práxis impulsionaram o } \\
\text { processo de mudança do controle gerencial em uma Cooperativa de Santa } \\
\text { Catarina. Estudo de caso. Identificaram-se duas fontes de contradições: inefi- } \\
\text { ciência dos controles gerenciais realizados pela cooperativa e desalinhamento } \\
\text { de interesses entre gerentes e dirigentes, bem como entre gerentes do mesmo } \\
\text { nível hierárquico. Quanto às práxis humanas, concluiu-se que estas são ele- } \\
\text { mentos necessários para que a mudança ocorra, pois são os intermediadores do } \\
\text { processo. Conclui-se a implementação do planejamento estratégico está institu- } \\
\text { cionalizada, sendo as contradições institucionais as principais impulsionadoras } \\
\text { da mudança, e as práxis, elementos necessários para que a mudança ocorresse. }\end{array}$ \\
\hline
\end{tabular}
Fonte: os autores.

Identificaram aspectos fundamentais de hábitos e rotinas da contabilidade gerencial. Considerando a necessidade de entendimento da situação da empresa antes do processo de mudanças, durante o processo e após a implantação, os autores optaram por pesquisa-ação. A busca por respostas foi embasada nas teorias institucional e da contingência. Dos resultados apontados pelo caso estudado, destacam-se: a análise dos impactos de contingências ambientais, tornando ineficazes os hábitos e rotinas de contabilidade gerencial existentes; a dificulda-

Caráter exploratório. À luz da Teoria Neo institucional visam entender a adoção de artefatos de contabilidade gerencial no ambiente empresarial brasileiro. A amostra foi não probabilística e abrangeu 27 empresas de médio e grande portes. Utilizou-se estatística descritiva para a análise dos questionários. Cono mecanismo mimético é o mais importante na adoção desses artefatos; a obtenção do conhecimento sobre novos artefatos ocorre, preponderantemente, pela forma de socialização do conhecimento; as consultorias têm um papel importante na adoção dos artefatos; a imposição dos acionistas é pequena, sen-

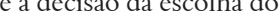

Analisaram o processo interno de mudança de sistemas de contabilidade gerencial em uma pequena empresa e examinaram como os aspectos desse os fatores que influenciaram positivamente a internalização da institucionalização dos sistemas de controle gerencial foram: os conhecimentos e habilidades envolvidos na mudança; os recursos de informática; a formação do pessoal; a baixa participação de peritos externos no sistema de controle gerencial; o incentivo dos operadores do sistema; as relações de confiança; o processo de planejamento e o envolvimento do pessoal.

Destacam que as pressões institucionais contribuem para as modificações na os diversos aspectos das instituições e seus respectivos processos de institucionalização.

Identifica como as contradições institucionais e as práxis impulsionaram o processo de mudança do controle gerencial em uma Cooperativa de Santa Catarina. Estudo de caso. Identificaram-se duas fontes de contradiçóes: ineficiência dos controles gerenciais realizados pela cooperativa e desalinhamento nível hieráquico. Quanto às práxis humanas, concluin-se que estas são elementos necessários para que a mudança ocorra, pois são os intermediadores do processo. Conclui-se a implementação do planejamento estratégico es túnstitucionalizada, sendo as contradições institucionais as principais impulsionadoras da muda ça e as práxis, clementos necessírios para que a mudanca ocorresse. 
Os estudos já realizados sobre as mudanças sob a ótica da teoria institucional apontam resultados e fatores de influência relacionados aos artefatos da contabilidade. Dessa forma, surge a lacuna de pesquisa, que trata de estudar a institucionalização das rotinas contábeis.

\section{ASPECTOS METODOLÓGICOS}

\subsection{CLASSIFICAÇÃO DA PESQUISA}

O estudo caracteriza-se como descritivo, quanto aos objetivos, pois visa à descrição das características de uma população e ao estabelecimento de possíveis relações entre variáveis (GIL, 2010). Buscou-se descobrir, relatar e analisar os fatores mais significativos relacionados com as mudanças institucionais, contradições institucionais e práxis nas rotinas contábeis. Possui ainda uma abordagem quantitativa, que segundo Malhotra (2001), procura quantificar os dados e geralmente aplica alguma forma estatística de análise. Neste estudo aplica-se a análise fatorial, além da análise de estatística descritiva dos dados.

\subsection{POPULAÇÃO E AMOSTRA}

A população da pesquisa compreende os 450 alunos de dois Cursos de graduação em Ciências Contábeis de uma universidade pública do Estado do Paraná. Por sua vez, a amostra compreende 43 alunos, os quais representam aqueles que estavam trabalhando na área da Contabilidade na data da coleta. A escolha da universidade ocorreu por acessibilidade.

\subsection{PROCEDIMENTOS DE COLETA E ANÁLISE DOS DADOS}

O método de coleta dos dados foi do tiposurvey; foi elaborado um questionário estruturado a partir dos modelos de Tolbert e Zucker (1999) e Seo e Creed (2002). Ele é composto por 10 questões para caracterizar os respondentes, 15 questões sobre mudanças institucionais, 20 questões sobre contradições institucionais, 10 sobre práxis e três questões abertas referentes às rotinas contábeis, conforme Quadro o 3. A avaliação das respostas referente às mudanças institucionais, contradições 
institucionais e práxis ocorreu por meio de escala intervalar (escala Likert de 5 pontos, entre Concordo fortemente e Discordo fortemente). Apresenta-se, a seguir, o referido Quadro 3, com o constructo da pesquisa.

Quadro 3 - Constructo de pesquisa

\begin{tabular}{|c|c|c|c|}
\hline Assunto & Questões & Tipo & Autores \\
\hline Características do respondente & 10 questões & $\begin{array}{l}\text { Aberta } \\
\text { cat. }\end{array}$ & $\begin{array}{l}\text { Elaboradas pelos autores deste } \\
\text { artigo }\end{array}$ \\
\hline Mudanças Institucionais & & & Tolbert e Zucker (1999) \\
\hline $\begin{array}{l}\text { Legislação; mudanças tecnológicas e } \\
\text { forças do mercado }\end{array}$ & $\begin{array}{l}1 \text { a } 5 ; 6 \text { a } 10 \\
\text { e } 11 \text { a } 15\end{array}$ & Likert & $\begin{array}{l}\text { Com base em Tolbert e Zucker } \\
\text { (1999) }\end{array}$ \\
\hline Contradições Institucionais & & & Seo e Creed (2002) \\
\hline \multirow{2}{*}{ Ineficiência técnica } & 16 & Likert & Com base em Seo; Creed (2002) \\
\hline & 17 a 20 & Likert & Adaptado de Oliveira (2004) \\
\hline \multirow[b]{2}{*}{ Não adaptabilidade } & 21 a 23 & Likert & Com base em Seo; Creed (2002) \\
\hline & 24 e 25 & Likert & $\begin{array}{l}\text { Com base em Resende Júnior, } \\
\text { Guimarães e Bilhim (2013) }\end{array}$ \\
\hline Incompatibilidade institucional & 26 a 30 & Likert & \multirow{2}{*}{ Com base em Seo e Creed (2002) } \\
\hline Desalinhamento de interesses & 31 a 35 & Likert & \\
\hline Práxis & 36 a 45 & Likert & $\begin{array}{l}\text { Com base Seo; Creed (2002) e } \\
\text { Resende Júnior; Guimarães e } \\
\text { Bilhim (2013) }\end{array}$ \\
\hline Descritivas das rotinas & 3 questões & Abertas & $\begin{array}{l}\text { Elaboradas pelos autores deste } \\
\text { artigo }\end{array}$ \\
\hline
\end{tabular}

Fonte: adaptado de Tolbert e Zucker (1999), Seo e Creed (2002), Oliveira (2004) e Resende Júnior, Guimarães e Bilhim (2013).

Para verificar a coerência e principalmente o entendimento das variáveis por parte do entrevistado, realizou-se um pré-teste com quatro profissionais da área da Contabilidade, em que se constataram dificuldades de entendimento, sendo necessária a adequação de algumas questões antes da aplicação. Assim, a coleta de dados teve início logo após a realização dos pré-testes e adequação do questionário, no dia 13 de junho de 2014. Do total de 450 alunos, obtiveram-se 43 respostas, representando uma taxa de retorno de $9,55 \%$.

Os dados foram tabulados e posteriormente exportados para o software Statistical Package for the Social Sciences (SPSS) versão 21, utilizado para as análises estatísticas. Para analisar os dados coletados, foi aplicada a análise fatorial exploratória. A análise fatorial é uma técnica de análise exploratória de dados, que tem por objetivo identificar e analisar um conjunto de variáveis inter-relacionadas que podem, de 
alguma, forma representar as variáveis originais (MAROCO, 2003). O propósito da análise fatorial é a redução do número de variáveis pela construção de "fatores" - novas variáveis, com o mínimo de perda de informações, isto é, objetiva-se a eliminação da redundância, se existir, do grupo original de variáveis. O estudo partiu das 45 questões elaboradas com base no modelo de Tolbert e Zucker (1999) e Seo e Creed (2002), conforme detalhado no Quadro 3.

Optou-se pelo uso do método de análise de componentes principais com rotação Varimax, que permite a redução de variáveis ou a redução de fatores. Conforme mencionam Hair Junior. et al. (2005), buscou-se uma seleção de cargas fatoriais mais significativas, escolhendo as que apresentaram valores acima de 0,500 (corte das cargas fatoriais), para que os resultados não ficassem muito distribuídos. Também se escolheu eigen values (valores próprios) acima de 1,0, ou seja, retém-se apenas os fatores que apresentam valores próprios maiores que 1 , obedecendo ao critério de normalização de Kaiser.

Realizou-se o teste de Kaiser-Meyer-Olkin (KMO), para indicar o grau de explicação dos fatores encontrados, e o de esferidade de Barlett, que mostra a existência de relação suficiente entre os indicadores para a aplicação da análise fatorial, além da significância. Por fim, realizou-se o teste de Alpha de Cronbach, para verificar o grau de consistência das informações. Os testes realizados indicaram adequados resultados e serão apresentados na análise dos resultados. $\mathrm{Na}$ análise dos resultados descreveu-se, com base no referencial teórico abordado e estudos anteriores, a análise dos fatores de contradição institucional e práxis humanas mais significativos para as mudanças institucionais na Contabilidade.

\section{RESULTADOS}

Esta seção descreve o estudo realizado, relatando os fatores mais significativos de mudanças e contradições institucionais e práxis referentes às rotinas contábeis. Os resultados são descritos por meio da análise fatorial, e os fatores analisados foram construídos com base no referencial teórico. Os modelos de Tolbert e Zucker (1999) e de Seo e Creed (2002) serviram como estrutura para a análise dos resultados. 


\subsection{ESTATÍSTICA DESCRITIVA}

A pesquisa é composta por 43 questionários válidos, 17 respondidos por homens e 26, por mulheres; 29 eram profissionais que atuavam em escritório de contabilidade e 14, na contabilidade de alguma empresa. Em relação ao tempo de atuação na função, 38 responderam que possuíam até cinco anos, três responderam que tinham de seis a 10 anos e um, mais de 20 anos de atuação. Dos respondentes, 32 indicaram que possuem idade até 25 anos, oito responderam que possuem idade de 26 a 30 anos e três, acima de 31 anos.

Percebe-se que a maioria dos profissionais pesquisados possui até cinco anos na função, tem idade de até 25 anos e trabalha em escritório de contabilidade e não empresa, visto que a maioria atua como auxiliares contábeis. Assim, a respeito da função, 33 responderam que atuam como auxiliares contábeis e nove como auxiliares administrativos, consultores da área contábil, contadores, gerentes contábeis e de suporte de sistemas na área Contábil. Dos respondentes, 21 mencionaram que possuíam acima de dois anos de atuação naquela empresa ou escritório e cinco acima de cinco anos.

A Tabela 1 apresenta a estatística descritiva das mudanças institucionais. Observa-se que ocorreu variabilidade das respostas (mínimo e máximo) quanto às mudanças provocarem ou não grandes alterações nas rotinas. Constatou-se que para cada mudança elencada nas questões, obtiveram-se resultados médios entre 3,19 (Q12 - Fornecer serviços de auditoria para clientes) e 4,40 (Q9 - Lenta conexão de internet).

Assim, percebe-se que as rotinas para a execução dos serviços contábeis possuem dependência da internet. Como não são todos os clientes que necessitam de serviços de auditoria, essa mudança teve a menor média de efeito nas mudanças de rotinas e, consequentemente, menor escala de estímulo à inovação institucional. Entretanto, quando esse serviço é exercido, pode provocar grandes mudanças nas rotinas contábeis. Constata-se, ainda, que todas as mudanças apresentadas no construto (Q1 a Q15) possuem média que representa que elas mais afetam do que não afetam as rotinas. $\mathrm{O}$ maior desvio padrão foi de 1,17 , na questão 15 , a qual questão apresentou média de 3,33. As demais informações estão na Tabela 1. 
Tabela 1 - Estatística descritiva das mudanças institucionais

Fatores - mudanças institucionais:

Mín. Máx. Méd. DP

Legislação

Q1 - Sistema Público de Escrituração Digital (SPED).

$\begin{array}{llll}1 & 5 & 3,74 & 0,98\end{array}$

Q2 - Normas de contabilidade do Comitê de Pronunciamentos

Contábeis (CPC).

Q3 - Obrigações acessórias.

Q4 - Legislação tributária estadual.

Q5 - Legislação tributária federal.

$153,44 \quad 0,80$

Mudanças Tecnológicas

Q6 - Novo sistema de informática/módulo.

Q7 - Atualizações no sistema de informática/módulo.

Q8 - Novas máq./equip./computadores com tecnologia mais avançada.

Q9 - Lenta conexão de internet.

Q10 - Alterações no sistema de informação utilizado pelos

clientes.

$1 \quad 5 \quad 3,91 \quad 0,92$

$\begin{array}{llll}1 & 5 & 3,95 & 0,97\end{array}$

$154,00 \quad 0,93$

Forças do mercado

Q11 - Fornecer serviços de consultoria para clientes. $\quad \begin{array}{llll}1 & 5 & 3,33 & 0,97\end{array}$

Q12 - Fornecer serviços de auditoria para clientes. $\quad \begin{array}{llll}1 & 5 & 3,19 & 0,93\end{array}$

Q13 - Atendimento aos clientes para explicar procedimentos. $\quad \begin{array}{llll}1 & 5 & 3,53 & 1,08\end{array}$

Q14 - Entrada de novos clientes. $\quad \begin{array}{llll}1 & 5 & 3,77 & 1,04\end{array}$

Q15 - Visita às empresas dos clientes. $\quad \begin{array}{llll}1 & 5 & 3,33 & 1,17\end{array}$

Fonte: os autores.

A estatística descritiva das contradições institucionais, na Tabela 2, apresenta que a menor média $(2,72)$ de concordância com a afirmação de que o fato é uma contradição a qual provoca mudanças nas rotinas está na afirmação da questão 25. A questão 15 teve a maior média $(3,93)$. As incompatibilidades institucionais e o desalinhamento de interesses foram as contradições institucionais que mais provocam mudanças nas rotinas dos respondentes. 
Tabela 2 - Estatística descritiva das contradições institucionais

Fatores - contradições institucionais:

Mín. Máx. Méd. DP

Ineficiência técnica

Q16 - Rotinas que não atendem políticas (crenças e valores) da empresa.

$\begin{array}{lll}1 & 5 & 2,811,03 \\ 1 & 5 & 3,930,99 \\ 1 & 5 & 3,790,97 \\ 1 & 5 & 3,530,85 \\ 1 & 5 & 3,370,98\end{array}$

Expedição.

Não adaptabilidade

Q21 - Possíveis rotinas não realizadas por não serem necessidades dos clientes.

$153,470,85$

Q22 - Rotinas não aceitas pelos clientes.

$1 \quad 5 \quad 3,140,99$

Q23 - Novas formas de realizar tarefas não aceitas pelos clientes.

$153,090,84$

Q24 - Métodos de trabalho a partir de experiências bem-sucedidas

em outros escritórios/empresas não foram bem incorporados por

funcionários e clientes.

Q25 - Implementação de sistema informatizado a partir de experiências bem-sucedidas em outros escritórios/empresas não foram bem incorporadas pelos funcionários e clientes.

Incompatibilidade institucional

Q26 - Alterações/distribuições de tarefas entre setores/células fiscal e contábil.

$1 \quad 5 \quad 3,721,03$

Q27 - Prática malsucedida no depart. gerou conflitos em outros depart. $\quad \begin{array}{lll}1 & 5 & 3,161,09\end{array}$

Q28 - Relação conflit. opiniões (pess./profiss.) com pessoas de nível

hierárq. similar.

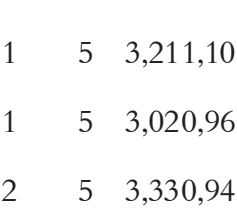

Q29 - Cobranças realizadas pelo depart. geram conflitos nos depart. subordinados.

Q30 - Ações executadas pelo depart. geram conflitos nos depart.

superiores.

Desalinhamento de interesses

Q31 - Interesses divergentes entre sócios do escritório/empresa.

$153,121,14$

Q32 - Interesses divergentes dos gerentes do escritório/empresa.

$153,091,17$

Q33 - Interesses divergentes entre colegas de trabalho.

$153,120,96$

Q34 - Interesses entre funções de nível hierárq. diferentes (superiores com inferiores).

$1 \quad 5 \quad 3,210,94$

Q35 - Interesses divergentes entre antigos e novos gerentes.

$153,001,05$

Fonte: os autores. 
Como as práxis humanas, conforme Seo e Creed (2002), são caracterizadas como principais mediadores entre as contradições e a mudança institucional, percebe-se a presença delas, pois apenas uma média foi abaixo de $3(2,77)$, referente à questão 41. As demais médias estão na Tabela 3 , na qual se destaca que uma práxis humana presente no estudo é o apoio dos superiores para auxiliar na solução de problemas (média 4,05, ou seja, os respondentes concordam com a afirmação). Segue a Tabela 3, com a estatística descritiva das práxis.

Tabela 3 - Estatística descritiva das práxis

\section{Fatores - práxis}

Q36 - Grupos de trabalho desenvolvem novos serviços no escritório/empresa.

Q37 - São realizadas ações para manter bom relacionamento com organizações parceiras.

Q38 - Novos funcionários são contratados com base nas competências essenciais à organização.

Q39 - No escritório/empresa há a contratação de pessoas princi-

palmente porque se visa atender às necessidades futuras.

Q40 - Existem ações coletivas que geram melhorias no escritório/empresa.

Q41 - Existem práticas de sistematização das reclamações dos usuários para melhoria do desempenho.

Q42 - Reuniões proporcionam grandes mudanças nas rotinas.

Q43 - Treinamentos proporcionam grandes mudanças nas rotinas.

Q44 - Apoio dos super. hierárq. auxilia na solução de problemas relac. com o trabalho.

Q45 - Qualificações dos empregados com vistas a aprimorar os serv. perceptíveis aos clientes.
Mín. Máx. Méd. DP

\begin{tabular}{llll}
1 & 5 & 3,12 & 0,98 \\
1 & 5 & 3,58 & 0,98 \\
1 & 5 & 3,79 & 0,91 \\
1 & 5 & 3,37 & 1,05 \\
1 & 5 & 3,60 & 0,95 \\
1 & 5 & 2,77 & 1,07 \\
1 & 5 & 3,19 & 0,93 \\
1 & 5 & 3,40 & 0,95 \\
1 & 5 & 4,05 & 1,02 \\
2 & 5 & 3,79 & 0,77 \\
\hline & & &
\end{tabular}
Fonte: os autores.

Percebe-se que os fatores que mais podem proporcionar mudanças estão relacionados à entrada de novos funcionários e suas qualificações e às ações dos líderes ou supervisores para a solução de problemas. Após a análise descritiva, elencaram-se componentes que representam o conjunto de afirmações ou questões mais significativas no estudo. Esses resultados foram encontrados por meio da análise fatorial, detalhada na sequência. 


\subsection{FATORES INSTITUCIONAIS DAS MUDANÇAS, CONTRADIÇÕES E PRÁXIS NA CONTABILIDADE}

Os dados das respostas das questões relacionadas às rotinas contábeis foram elencados por meio da análise fatorial. Assim, foram obtidos cinco fatores para as mudanças institucionais e oito fatores com poder de explicação das contradições institucionais e práxis, usando-se o critério de se considerar apenas os fatores com autovalores maiores que 1,0 e cargas fatoriais iguais ou superiores a 0,500. A matriz de componentes da análise fatorial das mudanças nas rotinas contábeis apresenta-se na Tabela 4, a seguir.

Tabela 4 - Matriz de componentes da análise fatorial das mudanças nas rotinas contábeis

(continua)

\section{Matriz de componente rotativa}

Mudanças nas rotinas contábeis

\section{Componente}

$\begin{array}{lllll}1 & 2 & 3 & 4 & 5\end{array}$

Q1 - Legislação: SPED

, 716

Q3 - Legislação: Obrigações acessórias

Q11 - Forças de mercado: Fornecer serv. de consultoria para clientes para clientes

Q13 - Forças de mercado: Atend. aos clientes p/ explicar procedim.

Q14 - Fatores de mercado: Entrada de novos clientes

Q2 - Legislação: Normas de contabilidade do CPC

Q4 - Legislação tributária estadual

Q5 - Legislação tributária federal

Q7 - Mudanças tecnológicas: Atualiz. no sist. de informática/módulo

Q15 - Forças de mercado: Visita às empresas dos clientes 


\section{Matriz de componente rotativa}

\section{Mudanças nas rotinas contábeis}

\section{Componente}

$\begin{array}{lllll}1 & 2 & 3 & 4 & 5\end{array}$

Q6 - Mudanças tecnológicas: Novo sistema de informática/módulo

Somas rotativas de carregamento ao quadrado (\% variância)

Somas rotativas de carregamento ao quadrado (\% variância acumul.)

862

Kaiser-Meyer-Olkin (KMO)

$23,6 \quad 15,6 \quad 12,7 \quad 12,4 \quad 9,1$

$23,6 \quad 39,3 \quad 52,0 \quad 64,4 \quad 73,6$

Teste de esferidade de Barlett Qui-quadrado aprox.

Método de extração: Análise do componente principal. Método de rotação: Varimax com normalização de Kaiser.a

Fonte: dados da pesquisa.

Nota: a - Rotação convergida em oito iterações.

Foram utilizadas todas as questões, simultaneamente, na análise fatorial na busca da criação de fatores; o grau de explicação dos fatores encontrados ocorreu pelo teste de Kaiser-Meyer-Olkin (KMO). Caso o KMO tivesse um grau de explicação menor que 0,50, significaria que os fatores encontrados não conseguiriam, satisfatoriamente, descrever as variações dos dados originais. Entretanto, neste estudo, quanto às mudanças institucionais, o KMO encontrado foi 0,696, o que é considerado por Pereira (2004) uma razoável explicação.

O teste de esferidade de Barlett foi realizado para verificar se existe relação suficiente entre as questões para a aplicação da análise fatorial, de forma que o valor do teste de significância (Sig.) ultrapassando 0,05 demonstraria provável pequena correlação e impedimento da realização da análise. Dessa forma, considerou-se adequada a significância apresentada pelo estudo (0,000). As informações mostram consistência e validade, pelo fato de apresentarem adequado Alfa de Cronback $(0,838)$.

$\mathrm{Na}$ Tabela 4 os fatores são apresentados, nomeados e seguem alguns comentários no sentido de interpretá-los. O que se busca é caracterizar cada fator por uma propriedade que possa representar a síntese de cada agrupamento estatístico. É importante ressaltar que essa caracterização não representa uma consequência matemática, mas, uma interpretação segundo uma visão geral do instrumento e dos conhecimentos relativos ao campo de saber que está inserido ou se refere. 
Com efeito, é a parte mais difícil da análise, pois envolve o julgamento subjetivo do avaliador da pesquisa.

Nesse sentido, a seguir é apresentada uma relação dos fatores que puderam ser nomeados e interpretados: Fator 1: Mudanças institucionais provocadas pelos fatores de mercado e legislação; Fator 2: Mudanças institucionais provocadas pela legislação; Fator 3: Mudanças institucionais provocadas por mudanças tecnológicas e de mercado; Fator 4: Mudanças institucionais relacionadas às mudanças tecnológicas; Fator 5: Mudanças institucionais provocadas por novo sistema de informática/módulo.

Ao analisar os elementos que compõem o Fator 1, que corresponde a 23,645\% da variância, ou seja, 32,107\% da variância total (73,643\%), tratam-se dos aspectos relacionados aos fatores de mercado e legislação. Ao interpretar o Fator, nota-se que as alterações na legislação possuem peso nas influências de mudanças nas rotinas. $\mathrm{O}$ Fator 2 figura os aspectos relacionados especificamente à legislação (15,698\% da variância). Dessa forma, os Fatores 1 e 2 representam 39,343\% da variância. Portanto, quanto mais ocorrem alterações na legislação, por exemplo, estadual ou federal, mais haverá a influência para a inovação.

Das mudanças apontadas no Fator 1, a ordem de poder de explicação é a seguinte: Fatores de mercado: Fornecer serviços de consultoria para clientes $(0,799)$, Entrada de novos clientes $(0,755)$ e Atendimento aos clientes para explicar procedimentos (0,750); Legislação: $\operatorname{SPED}(0,716)$; Fatores de mercado: Fornecer serviços de auditoria para clientes $(0,677)$ e Legislação: Obrigações acessórias $(0,579)$.

Constata-se que ao ser realizada uma consultoria ou, então, ao existir uma diferente ou nova legislação, isso proporciona as maiores mudanças nas situações de rotina do escritório e dos profissionais. Realizar consultoria e pesquisar legislações representam rotinas novas e que exigem do indivíduo algo diferente daquilo habitualmente realizado por ele. Com a existência frequente de nova legislação, percebe-se que os profissionais podem estar constantemente convivendo com mudanças. De forma semelhante, escritórios e profissionais que costumam realizar consultorias convivem com desafios diferentes da rotina e, consequentemente, com uma dinâmica profissão, referente às atividades realizadas.

Os Fatores 3, 4 e 5 estão fortemente relacionados com mudanças tecnológicas (de sistemas, módulos, computadores e equipamentos e conexão na internet). Esses elementos apontaram pelo fato de que as atividades da Contabilidade são realidades, quase na totalidade, por meio de sistemas de informações e conexão da internet. $\mathrm{Na}$ Tabela 5, a seguir, apresenta-se a matriz de componentes da análise fatorial das mudanças nas rotinas contábeis. 
Tabela 5 - Matriz de componentes da análise fatorial das mudanças nas rotinas contábeis

\begin{tabular}{|c|c|c|c|c|c|c|c|c|}
\hline \multicolumn{9}{|c|}{ Matriz de componente rotativaa } \\
\hline \multirow{2}{*}{$\begin{array}{c}\text { Contradições institucionais e } \\
\text { práxis }\end{array}$} & \multicolumn{8}{|c|}{ Componente } \\
\hline & 1 & 2 & 3 & 4 & 5 & 6 & 7 & 8 \\
\hline $\begin{array}{l}\text { Q27 - Incompatibilidade insti- } \\
\text { tucional }\end{array}$ &, 514 & & & & & & & \\
\hline $\begin{array}{l}\text { Q28 - Incompatibilidade insti- } \\
\text { tucional }\end{array}$ & ,754 & & & & & & & \\
\hline $\begin{array}{l}\text { Q29-Incompatibilidade insti- } \\
\text { tucional }\end{array}$ & ,665 & & & & & & & \\
\hline $\begin{array}{l}\text { Q31 - Desalinhamento de inte- } \\
\text { resses }\end{array}$ & ,781 & & & & & & & \\
\hline Q32 - Desalinhamento de inte- &, 817 & & & & & & & \\
\hline $\begin{array}{l}\text { Q33 - Desalinhamento de inte- } \\
\text { resses }\end{array}$ & ,900 & & & & & & & \\
\hline Q34 - Desalinhamento de inte- & ,799 & & & & & & & \\
\hline $\begin{array}{l}\text { Q355- Desalinhamento de inte- } \\
\text { resses }\end{array}$ & ,779 & & & & & & & \\
\hline Q36 - Práxis & & ,694 & & & & & & \\
\hline Q37 - Práxis & & ,780 & & & & & & \\
\hline Q38 - Práxis & & ,744 & & & & & & \\
\hline Q40 - Práxis & &, 851 & & & & & & \\
\hline Q41 - Práxis & & ,696 & & & & & & \\
\hline Q42 - Práxis & & ,713 & & & & & & \\
\hline Q44 - Práxis & &, 518 & & & & & & \\
\hline Q17 - Ineficiência técnica & & & ,827 & & & & & \\
\hline Q18 - Ineficiência técnica & & & ,890 & & & & & \\
\hline Q19 - Ineficiência técnica & & & ,836 & & & & & \\
\hline Q20 - Ineficiência técnica & & &, 525 & & & & & \\
\hline Q21 - Não adaptabilidade & & &, 568 & & & & & \\
\hline Q22 - Não adaptabilidade & & & & 812 & & & & \\
\hline Q23 - Não adaptabilidade & & & & ,769 & & & & \\
\hline Q24 - Não adaptabilidade & & & &, 569 & & & & \\
\hline Q25 - Não adaptabilidade & & & &, 510 & & & & \\
\hline Q43 - Práxis & & & & &, 735 & & & \\
\hline Q45 - Práxis & & & & & ,781 & & & \\
\hline Q16 - Ineficiência técnica & & & & & &, 533 & & \\
\hline $\begin{array}{l}\text { Q30 - Incompatibilidade insti- } \\
\text { tucional }\end{array}$ & & & & & &, 840 & & \\
\hline Q39 - Práxis & & & & & & & 697 & \\
\hline $\begin{array}{l}\text { Q26 - Incompatibilidade insti- } \\
\text { tucional } \\
\text { Somas rotativas de carregamento }\end{array}$ & 18,180 & 14,107 & 11,663 & 9,254 & 7,102 & 5,886 & 5,599 & $\begin{array}{r}, 661 \\
4,879\end{array}$ \\
\hline $\begin{array}{l}\text { ao quadrado (\% variância) } \\
\text { Somas rotativas de carregamento } \\
\text { ao quadrado (\% variância acu- } \\
\text { mulado) }\end{array}$ & 18,180 & 32,287 & 43,950 & 53,204 & 60,306 & 66,193 & 71,791 & 76,671 \\
\hline Kaiser-Meyer-Olkin (KMO) & ,488 & & & & & & & \\
\hline \multicolumn{9}{|c|}{ Teste de esferidade de Barlett Qui-quadrado aprox.: 872,994 } \\
\hline DF: $435 \quad$ Sig.: 0.000 & Alfa & de Cron & nbach: 0 & 0.858 & & & & \\
\hline
\end{tabular}


Conforme se demonstra na Tabela 5, para analisar os oito fatores encontrados sobre contradições institucionais e práxis, foram introduzidas todas as questões, simultaneamente, na análise fatorial exploratória e constatou-se que o KMO de 0,488 é considerado por Pereira (2004) de má explicação, ou seja, baixo poder de explicação entre os fatores e as questões. A significância (Sig.) apresentada pelo estudo $(0,000)$ é considerada adequada, assim como o Alfa de Cronback $(0,858)$ foi considerado adequado quanto à consistência das informações.

Uma vez apresentados os fatores, faz-se necessário nomeá-los e em seguida tecer alguns comentários no sentido de interpretá-los. O que se busca é caracterizar cada fator por uma propriedade que possa representar a síntese de cada agrupamento estatístico. É importante ressaltar que essa caracterização não representa uma consequência matemática, mas uma interpretação segundo uma visão geral do instrumento e dos conhecimentos relativos ao campo de saber do qual o fator se refere. Com efeito, é a parte mais difícil da análise, pois envolve o julgamento subjetivo do avaliador da pesquisa.

A relação dos fatores que puderam ser nomeados e interpretados é a seguinte: Fator 1: Contradições institucionais relacionadas ao desalinhamento de interesses e incompatibilidade institucional; Fator 2: Contradições institucionais relacionadas à práxis; Fator 3: Contradições institucionais relacionadas à ineficiência técnica; Fator 4: Contradições institucionais relacionadas à não adaptabilidade; Fator 5: Contradições institucionais relacionadas à práxis de treinamentos e qualificações; Fator 6: Contradições institucionais relacionadas a rotinas que não atendem às políticas e geram conflitos com departamentos superiores; Fator 7: Contradições institucionais relacionadas à práxis de contratação para a necessidade futura e Fator 8: Contradições institucionais relacionadas à incompatibilidade institucional de alteração na distribuição de tarefas.

Ao analisar os elementos que compõem o Fator 1, que corresponde a $18,180 \%$ da variância, ou seja, 23,71\% da variância total (76,671\%), tratam-se dos aspectos relacionados ao desalinhamento de interesses e à incompatibilidade institucional. Nota-se que o desalinhamento de interesses encontrado representa todas as afirmações sobre esse assunto, ou seja, sobre as cinco questões, além de ser o tipo de contradição com maiores pesos de explicação.

Entre os divergentes interesses encontrados na pesquisa, estão os que podem ser entre sócios, gerentes, colegas de trabalho, funções de níveis hierárquicos diferentes ou, ainda, entre antigos e novos gerentes. Por esse motivo, constata- 
se a importância da sinergia que deve existir entre os profissionais, bem como a importância de uma equipe consolidada e coesa.

Quanto ao Fator 2, que representa 14,107\% da variância, menciona-se que é relacionado com as práxis humanas. Interpreta-se esse fator como importante pelo fato de que estas são as principais mediadoras entre as contradições e a mudança institucional. As práxis humanas são existentes e possuem peso no estudo realizado. $\mathrm{Na}$ escala para a inovação pesquisada por Resende Júnior, Guimarães e Bilhim (2013), as práxis também foram encontradas como influentes.

Como os elementos da institucionalização são o indivíduo, a organização e o ambiente, conforme tratado por Boff, Beuren e Guerreiro (2008), os atores sociais estão presentes ao formularem ações estratégicas com base nos significados atribuídos às regras de funcionamento das organizações.

Os achados no Fator 1 e no Fator 3 também foram constatados por Popik (2013) em estudo de caso em cooperativa. Popik (2013) constatou que as contradições institucionais estão relacionadas com a ineficiência dos controles gerenciais e o desalinhamento de interesses entre gerentes e dirigentes, assim como entre gerentes do mesmo nível hierárquico, permitindo inferir que foram estas que estimularam a mudança no objeto pesquisado. A presença das contradições encontradas está de acordo com Guerreiro et al. (2005), ao tratarem que estão entre os fatores facilitadores que contribuem com o processo de mudança.

$\mathrm{Na}$ análise de comunalidade das variáveis, pelo método de extração do componente principal, todas entraram nos componentes, de forma que a consistência e a relevância das variáveis para o estudo foram representadas por não terem extração menor que $50 \%$. As menores comunalidades encontradas apresentaram extração de 0,590 para a Questão 1 sobre a mudança institucional referente à Legislação do SPED, quanto às mudanças que provocam inovações. A Questão 36 foi a que apresentou extração menor que $60 \%(0,593)$ e se refere à práxis da existência de grupos de trabalho que desenvolvem novos serviços no escritório/empresa.

\section{CONSIDERAÇÕES FINAIS}

Neste estudo objetivou-se identificar os fatores que proporcionam contradições, práxis e mudanças institucionais em rotinas contábeis. De acordo com o estudo, foi possível discorrer sobre um contexto específico das rotinas contábeis para os profissionais que atuam na área. Assim, restringindo-se os resultados à amostra 
analisada, elencaram-se os fatores com peso mais significativo e representativo diante das diversas mudanças institucionais pelas quais os profissionais passam.

Entre as mudanças institucionais, elencaram-se cinco fatores, os dois primeiros apresentando as mudanças provocadas pelos fatores de mercado e legislação e representando, juntos, 23,645\% da variância, ou seja, 32,107\% da variância total $(73,643 \%)$. Os demais fatores estão fortemente relacionados com mudanças tecnológicas (de sistemas, módulos, computadores e equipamentos e conexão na internet): Fator 3 (12,708\% da variância), Fator 4 (12,426\% da variância) e Fator 5 (9,167\% da variância). As mudanças nas rotinas contábeis são mais dependentes das alterações na legislação do que das alterações tecnológicas.

Os resultados permitem concluir que, além da existência de diferente ou nova legislação, outra mudança que proporciona maiores mudanças nas situações de rotina do escritório e dos profissionais é a realização de serviços de consultoria, pois representa um desafio no trabalho e na rotina.

$\mathrm{Na}$ análise dos fatores de contradições institucionais e práxis humanas, percebe-se que cada um dos oito fatores procurou reunir os tipos ou subdivisões semelhantes de contradições. Os três fatores mais representativos estão relacionados ao desalinhamento de interesses e à incompatibilidade institucional (Fator 1; $18,180 \%$ ), às práxis humanas (Fator 2; 14,107\%) e à ineficiência técnica (Fator 3; 11,663\%), com um acumulado de 43,45\%. Assim, conclui-se que existe a importância da sinergia entre os profissionais e entre suas equipes de trabalho, quando se trata de interesses divergentes.

Entre alguns dos estudos anteriores realizados, menciona-se que este aplica os modelos de Tolbert e Zucker (1999) e de Seo e Creed (2002), além de contribuir com estudos de Oliveira (2004), Guerreiro et al. (2005), Siti-Nabiha e Scapens (2005), Guerreiro, Pereira e Rezende (2006), Rocha e Guerreiro (2010), Popik (2013) e Resende Júnior, Guimarães e Bilhim (2013), por estudar mudanças específicas nas rotinas da prestação de serviços de contabilidade.

Dessa forma, não se pretende esgotar o assunto, mas apresentar a possibilidade de explorá-lo de modo mais aprofundado, envolvendo outros fatores preponderantes que possam interferir na relação entre as variáveis. 


\section{REFERÊNCIAS}

ABRAHAMSSON, G.; GERDIN, J. Exploiting institutional contradictions: The role of management accounting in continuous improvement implementation. Qualitative Research in Accounting \& Management, v. 3, i. 2. p. 126-144, 2006.

BENSON, J. K. Organizations: a dialectical view. Administrative Science Quarterly, v. 22, i. 1, p. 1-21, 1977.

BEUREN, I.; MACOHON, E. Institucionalização de hábitos e rotinas na contabilidade gerencial à luz da teoria da contingência: um estudo em indústrias de móveis em São Bento do Sul. Revista Portuguesa e Brasileira de Gestão, v. 10, n. 1-2, p. 78-91, 2011.

BJERREGAARD, T.; LAURING, J. Entrepreneurship as institutional change: strategies of bridging institutional contradictions. European Management Review, v. 9, p. 31-43, 2012.

BOFF, M. L.; BEUREN, I. M.; GUERREIRO, R. Institucionalização de hábitos e rotinas da controladoria em empresas do estado de Santa Catarina. Organizações \& Sociedade, O\&S, v. 15, n. 46, p. 153-174, jul./set. 2008.

BURNS, J.; BALDVINSDOTTIR, G. An institutional perspective of accountants' New Roles - the interplay of contradictions and praxis. European Accounting Review, v. 14, i. 4, p. 725-757, 2005.

BURNS, J.; SCAPENS, R. Conceptualising management accounting change: an institutional framework, forthcoming. Management Accounting Research, Londres, v. 11, p. 3-25, 2000.

BURNS, J. The dynamics of accounting change: inter-play between new practices, routines, institutions, power and politics. Accounting, Auditing \& Accountability Journal, Adelaide/Austrália, v. 13, i. 5, p. 566-596, 2000.

CHENHALL, R. H.; LANGFIELD-SMITH, K. The relationship between strategic priorities, management techniques and management accounting: an empirical investigation using a systems approach. Accounting, Organizations and Society, v. 23, i. 3, p. 243-264, 1998.

CLEMENS, E. S.; COOK, J. M. Politics and institutionalism: explaining durability and change. Annual Review of Sociology, v. 25, i. 1, p. 441-466, 1999. 
CONRAD, L.; USLU, P. G. Investigation of the impact of 'payment by results' on performance measurement and management in NHS Trusts. Management Accounting Research, i. 22, p. 4655, 2011.

CONSELHO FEDERAL DE CONTABILIDADE. Resolução n. 1.098, de 24 de outubro de 2007. Dispõe sobre o Registro Cadastral das Organizações Contábeis nos Conselhos Regionais de Contabilidade. Disponível em: <http://www. normaslegais.com.br/legislacao/resolucaocfc1098_2007.htm>. Acesso em: 05 jun. 2014.

COVALESKI, M. A.; DIRSMITH, M. W.; MICHELMAN, J. E. An institutional theory perspective on de DRG framework, case-mix accounting systems and health-care organizations. Accounting, Organizations and Society, v. 18, i. 1, p. 65-80, 1993.

CRUZ, I.; MAJOR, I.; SCAPENS, R. W. Institutionalization and practice variation in the management control of a global/local setting. Accounting, Auditing \& Accountability Journal, v. 22, i. 1, p. 91-117, 2009.

DILLARD, J. F.; RIGSBY, J. T.; GOODMAN, C. The making and remaking of organization context: Duality and the institutionalization process. Accounting, Auditing \& Accountability Journal, v. 17, i. 4, p. 506-542, 2004.

FREZATTI, F. et al. Controle Gerencial: uma abordagem da contabilidade gerencial no contexto econômico, comportamental e sociológico. São Paulo: Atlas, 2009.

GIL, A. C. Métodos e técnicas de pesquisa social. São Paulo: Atlas, 2010.

GUERREIRO, R. et al. Fatores determinantes do processo de institucionalização de uma mudança na programação orçamentária: uma pesquisa-ação em uma organização brasileira. Revista de Contabilidade do Mestrado em Ciências Contábeis da UERJ, v. 10, n. 1, 2005a.

GUERREIRO, R. et al. O entendimento da contabilidade gerencial sob a ótica da teoria institucional. Organizações \& Sociedade, O\&S, v. 35, p. 1-20, out./dez. 2005b.

GUERREIRO, R.; PEREIRA, C. A.; REZENDE, A. J. Em busca do entendimento da formação dos hábitos e das rotinas da contabilidade gerencial: um estudo de caso. Revista de Administração Mackenzie, v. 7, n. 2, 2006.

HAIR JUNIOR, J. F. et al. Análise multivariada de dados. 5. ed. Tradução Adonai Schlup Sant'ana e Anselmo Chaves Neto. Porto Alegre: Bookman, 2005. 
LAVARDA, C. E. F.; RIPOLL FELIU, V. M.; BARRACHINA PALANCA, M.

La Interiorización del Cambio de un Sistema Contable de Gestión en la Pequeña Empresa. Revista Contabilidade \& Finanças - USP, São Paulo, v. 20, n. 51, p. 101-115, set./dez. 2009.

LOPES, A. B.; IUDÍCIBUS, S. Teoria avançada da contabilidade. São Paulo: Atlas, 2012.

MACHADO-DA-SILVA, C. L.; GONÇALVES, S. A. Nota técnica: a teoria institucional. Handbook de estudos organizacionais. São Paulo: Atlas, 1999. v. 1.

MAJOR, M. J.; RIBEIRO, J. A teoria institucional na investigação em contabilidade. In: MAJOR, M. J.; VIEIRA, R. Contabilidade e Controle de Gestão: Teoria, Metodologia e Prática. Lisboa: Escolar Editora, 2009.

MALHOTRA, N. K. Pesquisa de marketing: uma orientação aplicada. Tradução Nivaldo Montingelli Junior e Alfredo Alves de Farias. Porto Alegre: Bookman, 2001.

MAROCO, J. Análise estatística com utilização do SPSS. Lisboa: Silabo, 2003.

MARTINS-COSTA, J.; BRANCO, G. Diretrizes teóricas do novo código civil brasileiro. São Paulo: Saraiva, 2002.

\section{OLIVEIRA, U. R. A correlação entre a remuneração por resultados e}

a satisfação dos funcionários: um estudo de caso no banco exemplo. 2004. Dissertação (Mestrado em Sistema de Gestão)-Universidade Federal Fluminense, Niterói, 2004.

OYADOMARI, J. C. et al. Fatores que influenciam a adoção de artefatos de controle gerencial nas empresas brasileiras: um estudo exploratório sob a ótica da teoria institucional. Revista de Contabilidade e Organizações, RCO, v. 2, n. 2, p. 55-70, jan./abr. 2008.

PECI, A. A nova teoria institucional em estudos organizacionais: uma abordagem crítica. Cadernos EBAPE. BR, n. 1, p. 1-12, 2006.

PEREIRA, A. Guia prático de utilização: análise de dados para ciências sociais e psicologia. 5. ed. Lisboa: Sílabo, 2004. 
POPIK, F. Contradições institucionais, práxis e mudança do controle gerencial: estudo de caso em uma Cooperativa de Santa Catarina. 2013. 108 p. Dissertação (Mestrado em Ciências Contábeis)-Universidade Regional de Blumenau, Blumenau, 2013.

REIS, L. G. A influência do discurso no processo de mudança da contabilidade: um estudo de caso sob o enfoque da teoria institucional. 2008. 187 p. Tese (Doutorado em Ciências Contábeis)-Universidade de São Paulo, São Paulo, 2008.

RESENDE JÚNIOR, P. C.; GUIMARÃES, T. A.; BILHIM, J. A. F. Escala de orientação para inovação em organizações públicas: estudo exploratório e confirmatório no Brasil e em Portugal. RAI - Revista de Administração e Inovação, São Paulo, v. 10, n. 1, p .257-277, jan./mar. 2013.

RIBEIRO, J.; SCAPENS, R. W. Institutional theories in management accounting change: Contributions, issues and paths for development. Qualitative Research in Accounting \& Management, v. 3, i. 2, p. 94-111, 2006.

ROCHA, W.; GUERREIRO, R. Desenvolvimento de modelo conceitual de sistemas de custos: um enfoque institucional. Revista de Contabilidade e Organizações, v. 4, n. 8, p. 24-46, 2010.

SCAPENS, R. W. Never mind the gap: towards an institutional perspective on management accounting practice. Management Accounting Research, v. 5, i. 3, p. 301-321, 1994.

SEO, M.; CREED, W. Institutional contradictions, praxis, and institutional change: a dialectical perspective. Academy of Management Review, v. 27, i. 2, p. 222247, 2002.

SHARMA, U.; LAWRENCE S.; LOWE, A. Institutional contradiction and management control innovation: A field study of total quality management practices in a privatized telecommunication company. Management Accounting Research, v. 21, i. 4, p. 251-264, 2010.

SITI-NABIHA, A. K.; SCAPENS, R. W. Stability and change: an institutionalist study of management accounting change. Accounting, Auditing \& Accountability Journal, v. 18, i. 1, p. 44-73, 2005.

SOUTES, D. O. Uma investigação do uso de artefatos da contabilidade gerencial por empresas brasileiras. São Paulo: 2006. Dissertação (Mestrado em Controladoria e Contabilidade)-Universidade de São Paulo, 2006. 
THOMÉ, I. Empresas de serviços contábeis: estrutura e funcionamento. São Paulo: Atlas, 2001.

TOLBERT, P. S.; ZUCKER, L. G. A institucionalização da teoria institucional. Handbook de estudos organizacionais, v. 1, p. 196-219, 1999.

WANDERLEY, C. A.; CULLEN, J. Um caso de mudança na contabilidade gerencial: a dinâmica política e social. Revista de Contabilidade $\boldsymbol{\&}$ Finanças, v. 23, n. 60, p. 161-172, 2012.

WANDERLEY, C. A. Institutional contradiction and the balanced scorecard: a case of unsuccessful change. In: ENCONTRO NACIONAL DA ASSOCIAÇÃO DOS PROGRAMAS DE PÓS-GRADUAÇÃO EM ADMINISTRAÇÃO, 37. 2012, Florianópolis. Anais... Florianópolis: ANPCONT, 2012.

WANDERLEY, C. A. et al. Management accounting change: a model based on three deferent theoretical frameworks. BASE Revista de Administração e Contabilidade da Unisinos, v. 8, n. 2, p. 111-121, abr./jun. 2011.

\section{COMO CITAR ESTE ARTIGO:}

WRUBEL, Franciele; TOIGO; Leandro Augusto; LAVARDA, Carlos Eduardo Facin. Mudanças nas rotinas contábeis: contradições institucionais e práxis humanas. RACE, Revista de Administração, Contabilidade e Economia, Joaçaba: Ed. Unoesc, v. 14, n. 3, p. 1175-1204, set./dez. 2015. Disponível em: $<$ http://editora.unoesc.edu.br/index.php/race > . Acesso em: dia/mês/ano.

Wrubel, F., Toigo, L. A., \& Lavarda, C. E. F. (2015). Mudanças nas rotinas contábeis: contradições institucionais e práxis humanas. RACE, Revista de Administração, Contabilidade e Economia, 14(3), p. 1175-1204, 26. Recuperado em dia/ mês/ano, de http://editora.unoesc.edu.br/index.php/race 